\title{
Driving Factors on the Adoption of Low Carbon Production: Evidence from 265 Enterprises Managers in Jiangsu Province of China
}

\author{
Yuanqing $\mathrm{Lu}^{1}$, Haiyan $\mathrm{Zhao}^{1}$, Fang Huang ${ }^{2}$ and Jin Wang ${ }^{3}$ \\ ${ }^{1}$ School of Public Administration, Nanjing University of Information Science \& \\ Technology ,Nanjing, 210044,China \\ ${ }^{2}$ School of Economics and Management, Nanjing University of Information Science \\ \&Technology, Nanjing, 210044, China \\ ${ }^{3}$ School of Computer and Software, Nanjing University of Information Science \& \\ Technology, Nanjing 210044, China
}

\begin{abstract}
It's the inevitably choice for enterprises to low carbon production, which is the important way to cope with the carbon limitation in the future and to gain competitiveness. Based on factor analysis, present paper developde low carbon production behavior questionnaire and investigated 265 enterprises managers in JiangsuProvince. Results of PLS test shows that: government policies, enterprise development, foreign trade have apparent effects on low carbon production behavior; the role of the public pressure to low carbon production behavior is not found. Through the driving factors analysis, present paper proposed some policy suggestions.
\end{abstract}

Keywords: low carbon production; drivingfactors; PLS-SEM

\section{Introduction}

Global climate change has become an important factor affecting the whole human being and low carbon future has become a global consensus gradually. Low carbon development, which can slow down the climate change and boost human sustainable development[1], is a rational model of development obviously[2]. Enterprises need pay for their carbon emissions generated by the production process in the future. For economic entity, lower carbon emissions can not only increase their wealth but also bring them more beautiful natural environment and welfare. It can be predicted that low carbon production will be the inevitable choice for the enterprise improvement in the future with the increasing pressure of carbon emissions reduction.

The developed countries have begun to promote low carbon production process from the beginning of 1980s. And a large number of researches also emerged, which were mainly concentrated on the factors affecting low carbon production, such as innovation, market, management features, policy environment etc. Gerard[3] found that both technological innovation and organizational human resource are relevant to cleaner production. Thomas and Karsten[4] also stressed the importance of technological innovation and proposed that the carbon trading frameworks impact on the enterprise carbon production. Luken[5] proposed that enterprises' low carbon production tendencies will regulated by the market measures to reduce carbon emissions. Frywell[6] thought that the carbon production process was affected by the knowledge 
and values of the business management. As for external environment, researchers have made a consensus that government policy played a major role in promoting low carbon production. And most studies emphasized the influence of environmental policies and specific measures, such as carbon label, carbon tariffs, energy consumption standards, etc.[7] Gadema and Zaina[8] found that UK's environmental policy affected the business's tendency to low carbon production, especially when clear guidance clues were provided by carbon label, which had an important role in promoting the low carbon production of UK food industry. Trappey[9] believed that the concern for environmental sustainability of the government, environmental groups and industry associations would encourage enterprises to reform their production methods. The green supply chain would be able to shorten the corporate carbon footprint and reduce the corporate's carbon emissions.

There are some researches focused on corporate low carbon production in China. But those researches about low carbon production mainly focused on macro-level, such as energy efficiency, industrial efficiency, staff efficiency. Zhang Tieshan found that value engineering had an important impact on the low carbon production of the corporate[10]. Liu Xianli and Chen Tao thought that technology innovation including product design, process optimization affected enterprise low carbon productiondirectly[11]. Hu Junnan and He Yqing considered that product management and capital operation play a key role in promoting low carbon development of the industrial enterprises[12]. Xu Jieming stressed that the establishment of a low carbon development goal can encourage the enterprise's low carbon production[13]. Through investigation, Zhu Ding, Wang Xiaoli, $\mathrm{Wu}$ Linhai and others proposed that the internal characteristics of enterprise managers, business size, technology innovation behavior, as well as enterprise exports and environmental certification and so on, affect the enterprises willingness of low carbon production[14] .

At present, there are few researches based micro-enterprise carbon production in China, mainly because China has no complete database of corporate carbon emissions which is difficult to obtain for the scholar. Therefore, the low carbon production tendency investigation is a reliable wayfor research the low carbon production. However, scholars lacked attention to the questionnaire design process and its scientific nature in the field of low carbon production. So some questionnaire design process were not objective nor logically. Present paper designed the enterprise carbon production behavior questionnaire by scientific process. Then the factors affected enterprise low carbon production were analyzed based on this questionnaire.

\section{The Development of Questionnaire}

\subsection{Measurement Methods and Theoretical Basis}

The measurement methods about enterprise behavior mainly included the annual report analysis, index analysis, professional organizations database, perception measurement, ect. The measurement of low carbon production behavior also need to learn from these methods and means. It is difficult to find useful data for few low carbon production information in exiting annual report. The index analysis about carbon emissions is scarce also. And the development of professional data is too lagging to obtain relate information in China, especially about enterprise carbon emissions. Neither of them can be used by present paper. 
The perception questionnairewhich is usually used in psychology reflects the corporate manager's cognition and subjective attitude to relevant items. This measurement mode needs to establish a theoretical model and segmented dimension, and then design the appropriate items to form a questionnaire to measure. The advantage of this method is easy to operate and have theoretical clarity. Of course, it also has some problems, such as low carbon behavioral tendencies does not always mean low carbon production behavior. But it is still a favorable measurement for scholars.

Present paper selected perception measurement for its convenience. Present paper design the questionnaire based on the theory of planned behavior, which was proposed by Icek Ajzen. Ajzen developed the new mode of behavior theory - - the planned behavior theory. In this framework, Ajzen thought the attitude can be the predictor of the behavior. In other words, behavior intention is determined by behavioral attitude, subjective norm and perceived behavioral control. The theory of planned behavior have been widely used in many fields.

\subsection{Design of Questionnaire}

The questionnaire of enterprise's low carbon production behavior is constructed by 3 dimensions: behavior attitude, subjective norm and perceived behavioral control of the enterprise managers. Present paper collected data by interview based on the theoretical construct. The interviews are focused on enterprise top managers and the doctoral students in Economic Management fields. Then 50 items were evaluated and modified by the doctoral student in Sociology or Psychology fields.Finally, 21 items were formed. There are good face validity in the questionnaire of enterprise low carbon production behavior. 5 point scoring is adopted and the items are randomized by present paper. In order to make exploratory factor analysis, the questionnaires were sent to 90 MBA students firstly. Then 80 questionnaires were finished by the MBA students and all of them were valid. At the same time, in order to confirmatory factor analysis and PLS-SEM construction, 400 questionnaires were sent in JiangsuProvince, 300 of them were recovered, 265 of them were valid.

\subsubsection{Exploratory Factor Analysis of the Questionnaire}

Exploratory factor analysis was conducted on the questionnaire results. 15 items are remained after deleting all the items that factor loadings are less than 0.5 or two public factor loadings are more than 0.5 . Cronbach's alpha reliability coefficient is $0.79, \mathrm{KMO}$ value $(0.73)$ is good. It meant that the questionnaire is suitable for exploratory factor analysis. Exploratory factor analysis extracted 3 factors (Table 2), the total variance explained is up to $65.92 \%$ (Table 1 ).

Table 1. Total Variance Explained

\begin{tabular}{|c|c|c|c|c|c|c|c|c|c|}
\hline \multirow[b]{2}{*}{ Component } & \multicolumn{3}{|c|}{ Initial Eigenvalues } & \multicolumn{3}{|c|}{ Extraction Sums of Squared Loadings } & \multicolumn{3}{|c|}{ Rotated Sums of Squared Loading } \\
\hline & Total & $\begin{array}{c}\% \text { of } \\
\text { Variance }\end{array}$ & $\begin{array}{c}\text { Cumulative } \\
\%\end{array}$ & Total & $\begin{array}{c}\% \text { of } \\
\text { Variance }\end{array}$ & $\begin{array}{c}\text { Cumulative } \\
\%\end{array}$ & Total & $\begin{array}{c}\% \text { of } \\
\text { Variance }\end{array}$ & $\begin{array}{c}\text { Cumulative } \\
\%\end{array}$ \\
\hline 1 & 5.26 & 34.10 & 34.10 & 5.26 & 34.10 & 34.10 & 3.87 & 25.81 & 25.81 \\
\hline 2 & 2.70 & 17.94 & 52.04 & 2.70 & 17.94 & 52.04 & 3.78 & 25.18 & 50.99 \\
\hline 3 & 1.93 & 13.03 & 65.07 & 1.93 & 13.03 & 65.07 & 2.24 & 14.93 & 65.92 \\
\hline
\end{tabular}


Table 2. Rotated Component Matrix

\begin{tabular}{|c|c|c|c|}
\hline \multirow{2}{*}{ Item } & \multicolumn{3}{|c|}{ Component } \\
\cline { 2 - 4 } & 1 & 2 & 3 \\
\hline $\mathrm{X} 6$ & .79 & .10 & .19 \\
\hline $\mathrm{X} 3$ & .78 & .15 & .05 \\
\hline $\mathrm{X} 4$ & .74 & .15 & -.04 \\
\hline $\mathrm{X} 5$ & .74 & .01 & .03 \\
\hline $\mathrm{X} 2$ & .66 & .19 & .01 \\
\hline $\mathrm{X} 7$ & .66 & .26 & .29 \\
\hline $\mathrm{X} 1$ & .28 & .80 & -.09 \\
\hline $\mathrm{X} 15$ & -.07 & -.79 & .07 \\
\hline $\mathrm{X} 10$ & .41 & .74 & .16 \\
\hline $\mathrm{X} 11$ & .35 & .72 & .06 \\
\hline $\mathrm{X} 9$ & .17 & .70 & .11 \\
\hline $\mathrm{X} 14$ & -.39 & .68 & .28 \\
\hline $\mathrm{X} 13$ & .14 & .12 & .92 \\
\hline $\mathrm{X} 12$ & .24 & -.16 & .85 \\
\hline $\mathrm{X} 8$ & -.19 & .52 & .64 \\
\hline
\end{tabular}

\subsubsection{Confirmatory Factor Analysis}

Amos 18.0 software was used to test the measurement model by present paper. It's necessary to point out that there was not general consensus about goodness of fit statistics of structural equation modeling. The goodness-of -fit index will be affected by the size of the sample. Therefore, we should not rely on a few fit index to evaluate the model's fitting degree. In order to evaluate the model more accurately, we should investigate both the sample size and actual situation. The normed chi-square $\left(\mathrm{X}^{2} / \mathrm{df}\right)$ value of the questionnaire is only 1.54 , indicates that the overall fit is very well; GFI value is 0.89 which is relatively weak but can meet the basic requirements. AGFI value is $0.84>0.8$, RMSEA value is 0.05 , IFI and CFI value are both greater than 0.90 (IFI=0.96, CFI=0.95) (shown in Table 3). Given relatively small samples size, the results is satisfied.

Table 3 Model Fit Summary

\begin{tabular}{|c|r|r|r|r|r|c|}
\hline Index & $\mathrm{X}^{2} / \mathrm{df}$ & \multicolumn{1}{c|}{ GFI } & \multicolumn{1}{c|}{ AGFI } & \multicolumn{1}{c|}{ RMSEA } & \multicolumn{1}{c|}{ IFI } & \multicolumn{1}{c|}{ CFI } \\
\hline Value & 1.54 & 0.89 & 0.84 & 0.05 & 0.96 & 0.95 \\
\hline
\end{tabular}

\section{Driving Factor and Quantitative Indicators}

\subsection{Hypothesis}

H1: Government has positive effect on enterprise's low carbon production behavior.

H2: Public pressure has a positive impact on enterprise's low carbon production behavior.

H3: Foreign trade has a positive impact on enterprise's low carbon production behavior. 
H4: Enterprise development has positive effect on enterprise's low carbon production behavior.

\subsection{Quantitative Indicators of Driving Factor}

Enterprise development: Low carbon production can effectively balance the social responsibility and enterprise profit. Many scholars admitted the enterprise can fulfill their responsibility only on the basis of certain level of profits. At the same time, it must consider innovation and development in the future when the enterprise developed to a certain stage.Therefore, scale and other factors of the enterprise will affect low carbon production behavior. Evaluation to the enterprise development is often based on the measurement of the enterprise performance, including financial, market and organization performance indicators. Present paper developed the 6 initial projects, including the subjective perception of annual sales, annual profit, staff size, etc.

Role of government: The government has played an important role in guiding the development and strategy of enterprises. As for the role of government, present paper constructed 6 projects including managers' perception on the government policy.

Public pressure: The voice of environmental protection will affect the enterprise production process. The design of the project is mainly used to measure weather the pressure of the public can be perceived by the enterprise manager and the influence on production activities. And 5 projects are formed then.

Foreign trade: Foreign trade indicators are mainly construct from two aspects: (1) foreign trade accounted for the proportion of the total sales of enterprise and (2) the perception of carbon trade barriers. 6 project are formed.

\subsection{Variable Test}

15 items were retained after reliability test. In order to ensure the dimensions corresponding to these items, KMO and Bartlett test were carried by present paper. Results shows that KMO is 0.67 , sphericity test of Bartlett is significant. That means factor analysis can be used for the data we collected. The four factors can explain $72.18 \%$ of the total variance. The factors structure is consisted with our theoretical predictions (Table 5).

Table 4. Total Variance Explained

\begin{tabular}{|c|c|c|c|c|c|c|c|c|c|}
\hline Component & \multicolumn{3}{|c|}{ Initial Eigenvalues } & \multicolumn{3}{|c|}{ Extraction Sums of Squared Loadings } & \multicolumn{3}{|c|}{ Rotated Sums of Squared Loading } \\
\hline & Total & $\begin{array}{c}\% \text { of } \\
\text { Variance }\end{array}$ & $\begin{array}{c}\text { Cumulative } \\
\%\end{array}$ & Total & $\%$ of Variance & $\begin{array}{c}\text { Cumulative } \\
\%\end{array}$ & Total & $\begin{array}{c}\% \text { of } \\
\text { Variance }\end{array}$ & $\begin{array}{c}\text { Cumulative } \\
\%\end{array}$ \\
\hline 1 & 4.35 & 28.97 & 28.97 & 4.35 & 28.97 & 28.97 & 3.65 & 24.31 & 24.31 \\
\hline 2 & 2.60 & 17.36 & 46.33 & 2.60 & 17.36 & 46.33 & 3.11 & 20.75 & 45.06 \\
\hline 3 & 2.36 & 15.75 & 62.08 & 2.36 & 15.75 & 62.08 & 2.36 & 15.70 & 60.76 \\
\hline 4 & 1.51 & 10.10 & 72.18 & 1.51 & 10.10 & 72.18 & 1.71 & 11.42 & 72.18 \\
\hline
\end{tabular}


Table 5. Rotated Component Matrix

\begin{tabular}{|c|c|c|c|c|}
\hline \multirow{2}{*}{ Item } & \multicolumn{4}{|c|}{ Component } \\
\cline { 2 - 5 } & 1 & 2 & 3 & 4 \\
\hline $\mathrm{a} 1$ & -.12 & .88 & -.08 & .16 \\
\hline $\mathrm{a} 2$ & -.08 & .82 & .10 & -.35 \\
\hline $\mathrm{a} 3$ & -.20 & .88 & .01 & .25 \\
\hline $\mathrm{a} 4$ & -.10 & .85 & -.01 & -.34 \\
\hline $\mathrm{b} 1$ & .76 & -.07 & -.13 & -.11 \\
\hline $\mathrm{b} 2$ & .82 & -.20 & .01 & -.12 \\
\hline $\mathrm{b} 3$ & .82 & -.05 & .16 & .33 \\
\hline $\mathrm{b} 4$ & .85 & -.01 & .05 & .14 \\
\hline $\mathrm{b} 5$ & .79 & -.27 & .16 & -.14 \\
\hline $\mathrm{c} 1$ & .14 & .08 & .75 & .08 \\
\hline $\mathrm{c} 2$ & .21 & -.11 & .66 & .20 \\
\hline $\mathrm{c} 3$ & .02 & -.01 & .84 & -.07 \\
\hline $\mathrm{c} 4$ & .21 & -.02 & -.72 & -.05 \\
\hline $\mathrm{d} 1$ & -.34 & -.18 & .03 & .77 \\
\hline $\mathrm{d} 2$ & .28 & .06 & .19 & .76 \\
\hline
\end{tabular}

\section{Driving Factors Test}

Present paper used VISUSL-PLS ( $1.04 \mathrm{a}$ version) soft to test the data by the Bootstrap algorithm. The index of PLS-SEM is mainly Rsq (Regression squared) and the results are shown in Figure 1. As can be seen from Figure 1, the Rsq value is 0.90, that means the model fit well and has explanation ability. Path coefficients standardized (significant ) are shown in Figure 1. All relations are verified by the PLS-SEM test, except for the relation between public pressure and low carbon production behavior, which need to be further discussed in the future.

The data reliability and validity were shown by the VISUAL-PLS. All internal consistency reliability of the 6 latent variables are above 0.7 , and most of them are more than 0.8 (Table 6). That means it suitable for further analysis. Most of the variables composite reliability ( $\mathrm{CR}$ ) values are more than 0.8 (Table 6), which is a satisfied result. Validity analysis is mainly divided into two categories: discriminant validity and convergent validity. Discriminant validity is shown in Table 7. Diagonal AVE value is more than the correlation coefficient between diagonal variable and other latent variables. Convergent validity is shown in Table 8 . All the convergent validity are more than 0.8 . These show that convergent validity and discriminant validity are both good in present paper. 


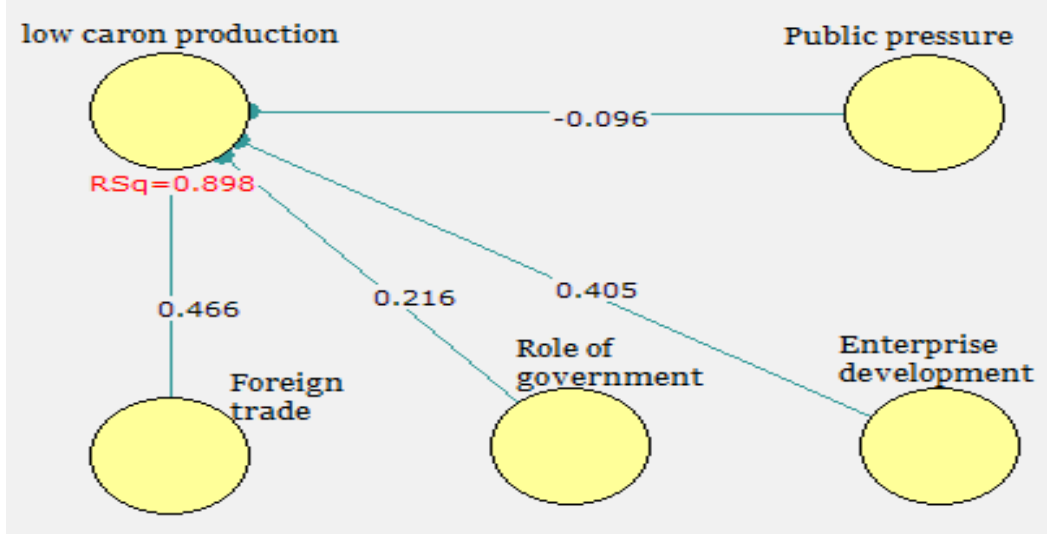

Figure 1. Driving Factors of Enterprise Low Carbon Production

Table 6. Variable Reliability (Cronbach'a Coefficient)

\begin{tabular}{|l|c|c|c|c|c|}
\hline & $\begin{array}{l}\text { Low cabon } \\
\text { production behavior }\end{array}$ & $\begin{array}{l}\text { Pubic } \\
\text { pressure }\end{array}$ & $\begin{array}{l}\text { Enterprise } \\
\text { development }\end{array}$ & $\begin{array}{l}\text { Role of } \\
\text { government }\end{array}$ & $\begin{array}{l}\text { Foreign } \\
\text { trade }\end{array}$ \\
\hline$C R$ & 0.76 & 0.96 & 0.88 & 0.91 & 0.95 \\
\hline Cronbach' $a$ & 0.77 & 0.92 & 0.82 & 0.86 & 0.91 \\
\hline
\end{tabular}

Table 7. Discriminant Validity

\begin{tabular}{|l|r|l|l|l|l|}
\hline & $\begin{array}{l}\text { Low cabon } \\
\text { production } \\
\text { behavior }\end{array}$ & $\begin{array}{l}\text { Pubic } \\
\text { pressure }\end{array}$ & $\begin{array}{l}\text { Enterprise } \\
\text { development }\end{array}$ & $\begin{array}{l}\text { Role of } \\
\text { government }\end{array}$ & $\begin{array}{l}\text { Foreign } \\
\text { trade }\end{array}$ \\
\hline $\begin{array}{l}\text { Low cabon production } \\
\text { behavior }\end{array}$ & 0.909 & & & & \\
\hline Pubic pressure & 0.907 & 0.923 & & & \\
\hline $\begin{array}{l}\text { Enterprise } \\
\text { development }\end{array}$ & 0.807 & 0.846 & 0.914 & & \\
\hline Role of government & 0.905 & 0.874 & 0.911 & 0.914 & \\
\hline Foreign trade & 0.913 & 0.944 & 0.921 & 0.909 & 0.959 \\
\hline
\end{tabular}

Table 8. Convergent Validity

\begin{tabular}{|c|c|c|c|c|}
\hline $\begin{array}{l}\text { Low carbon production } \\
\text { behavior }\end{array}$ & $\begin{array}{l}\text { Public } \\
\text { pressure }\end{array}$ & $\begin{array}{l}\text { Enterprise } \\
\text { development }\end{array}$ & $\begin{array}{l}\text { Role of } \\
\text { government }\end{array}$ & $\begin{array}{l}\text { Foreign } \\
\text { trade }\end{array}$ \\
\hline 0.83 & 0.85 & 0.83 & 0.71 & 0.92 \\
\hline
\end{tabular}

\section{Conclusions and Suggestion}

\subsection{Conclusions}

Present paper investigated 265 enterprise managers ( mainly be from Suzhou, Xuzhou, Wuxi and Nanjing) based on the low carbon production behavior questionnaire. The hypothesis were tested by PLS. We can draw the following conclusion: 
(1) Foreign trade affect enterprise's low carbon production behavior. The power which drove enterprise's low carbon production will be higher with the increase of percentage of the exports in enterprise sales proportion.

(2) Carbon limited policy of the government play a positive role in promoting enterprise low carbon production. The more stringent the policies limited, the more obvious the enterprise tend to low carbon production .

(3) Low carbon production tendency will be higher with the development of enterprise.

(4) Public pressure has no obvious affection on the enterprise low carbon production. The role of the public in promoting enterprise low carbon production is not notable.

\subsection{Suggestion}

(1) National carbon limitation polies should be promoted to provide fair carbon competition environment for enterprises. The development and implementation of carbon limitation policies should be enhanced, such as carbon access system and carbon market. The low carbon production enterprise will have more competitiveness than the others in this policy environment.

(2) Government should promote the development and utilization of low carbon productiontechnology. Enterprise which developed low carbon production should be approved by the government. Carbon fund should be established to provide enterprise low carbon technology. Government should provide intelligence platform to encourage enterprise to associate with university and other research institutions.

(3) Carbon label system should be constructed. The trials process about carbon label should be accelerated, so as to provide a basis for the public's low carbon consumption. Low carbon consumption education can be carried out through multiple medias and other channels to instruct people's consumption behavior.

\section{Acknowledgments}

This paper is a revised and expanded version of a paper entitled "Development of Low Carbon Production Behavior Questionnaire" presented at SoftTech 2014, Yeosu, Korea, May 8-10, 2014. This work was supported by the Industrial Strategic Technology Development Program (10041740) funded by the Ministry of Trade, Industry and Energy (MOTIE) Korea. It was also supported by the National Natural Science Foundation of China (61402234).

\section{References}

[1] H. Angang, "The new content from "green cat" model : low carbon economy", World Environment, vol. 2, (2008), pp.26-27.

[2] Z. Guiyang, "Analysis of Chinese ways and potential development of low carbon economy",Studies in international technology and economy,(2005), vol. 3, no. 8-12.

[3] G.I.J.M. Zwetsloot, N.A. Ashford, “The feasibility of encouraging inherently safter” , Safety Science, vol. 41, no. 2-3, (2003), pp. 219-240.

[4] "Carbon markets and technological innovation", Journal of Environmental Economics and Management, vol. 60, no. 2, (2010), pp. 115-132.

[5] R. Luken, V. Rompaey,F. Katar and N.A. Zigov, "The determinants of EST adoption by manufacturing plants in developing countries",Ecological Economics,(2008); pp. 66, vol. 1, pp.141-152.

[6] G.E. Fryxell and C.W.H. Lo, "The influence of environmental knowledge and values on managerial behaviours on behalf of the environment: an empirical examination of managers in China", Journal of Business Ethics, vol. 46, no. 1, (2003), pp. 45-69.

[7] K.A. Babakri, R.A. Bennett,S. Rao and W. Franchetti, "Recycling performance of firms before and after adoption of the ISO 14001 standard",Journal of Cleaner roduction,vol. 12, no. 6, (2004), pp.633-637. 
[8] Z. Gadema,"The use and usefulness of carbon labelling food: A policy perspective from a survey of UK supermarket shoppers", Food Policy, vol. 36, no. 6, (2011), pp. 815-822.

[9] A.J.C. Trappey, C. V. Trappey andC.-T. Hsiao, J. J.R. Ou andC.-T. Chang, "System dynamics modeling of product carbon footprint life cycles for collaborative green supply chains", International Journal of Computer Integrated Manufacturing, (2012), vol. 25, no. 10, pp. 934-945.

[10] Z. Tieshan, G. Huijie and Z. Chang, "Application of the value engineering to low-carbon production in industrial enterprises", Journal of industrial technological economics(In Chinese), vol. 4, (2012), pp. 50-54.

[11] L. Xianli and C. Tao, "Theory and technology of low-carbon manufacturing in machinery manufacturing", Journal of Harbin university of science and technology(In Chinese), (2011), vol. 1, no. 16, pp. 1-8.

[12] H. Junnan and H. Yiqing, "Study on the path and policy of low carbon development of Chinese industrial enterprises", vol. 12, (2011), pp.1-4.

[13] X. Jieming and X. Hongling, "Research on low carbon development goal indicators and implementation path of photovoltaic enterprise", Environment and Sustainable Development, vol. 1, (2012), pp. 41-46.

\section{Authors}

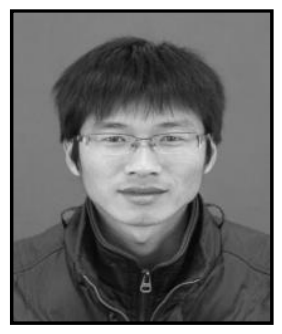

Yuanqing Lu. Yuanqing Lu obtained his Bachelor's degree in Education from HenanUniversity in 2002 in China, Master's degree in Science from NanjingNormalUniversity in 2005 in China.He received his Doctor in Management from HohaiUniversity in 2013 inChina. Now he is a associate professor in Nanjing University of Information Science and technology.His research interests mainly include management science and engineering.

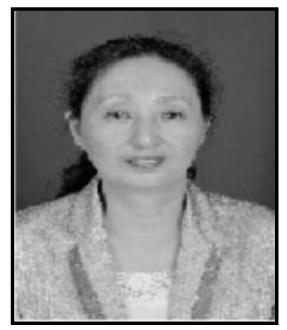

Haiyan Zhao. Haiyan Zhao obtained her Bachelor's degree in Mechanical Engineering from the SouthChinaAgriculturalUniversity in 1982. Now she is a professor in in Nanjing University of Information Science and technology. Her research interest includes management science and engineering, specifically in fields of organization communication and network.

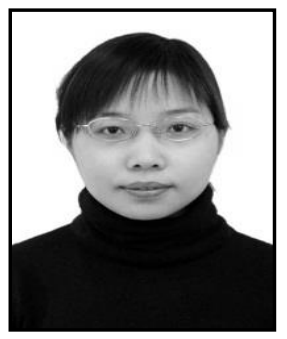

FangHuang. Fang Huang obtained her Bachelor's degree in Foreign Trade English from Nanjing University of Science and Technology in 2003 inChina, Master's degree in Management from Nanjing University of Science and Technology in 2005. She is a Ph.D candidate in Nanjing University of Aeronautics and Astronautics and a instructor in Nanjing University of Information Science and technology.Her research interests mainly include low carbon economics and management .

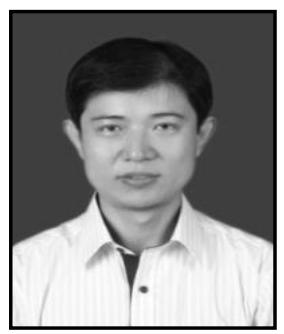

Jin WangDr. Jin Wang received the B.S. and M.S. degree in the Electronical Engineering from Nanjing University of Posts and Telecommunications, China in 2002 and 2005, respectively. He received Ph.D. degree from Kyung Hee UniversityKorea in 2010. Now, he is a professor in the Computer and Software Institute, Nanjing University of Information Science and Technology. His research interests mainly include routing protocol and algorithm design, performance evaluation and optimization for wireless ad hoc and sensor networks. He is a member of the IEEE and ACM. 
International Journal of $u$-and e-Services, Science and Technology Vol.7, No.5 (2014) 